\title{
A multilevel analysis of diet and socio-economic status in Scotland: investigating the 'Glasgow effect'
}

\author{
Linsay Gray* and Alastair H Leyland \\ MRC Social and Public Health Sciences Unit, 4 Lilybank Gardens, Glasgow G12 8RZ, UK
}

Submitted 30 0ctober 2007: Accepted 2 October 2008: First published online 25 November 2008

\begin{abstract}
Objective: To investigate differences between dietary habits in Glasgow and those in the rest of Scotland and the role that socio-economic factors have in explaining these.

Design: Data on age, sex, area deprivation, social class, educational qualifications, economic activity, health board region, postcode sector area and informants' usual intake of foods covering sugary foods, snacks, fibre, starch, meat, fish, spreading fats, dairy products, salt, dietary supplements, fruit and vegetables were available from the 1995, 1998 and 2003 Scottish Health Surveys. Multilevel logistic regression was used to model the relationship between diet and living in Greater Glasgow compared with elsewhere in Scotland, unadjusted and adjusted for age, survey year and socio-economic factors, accounting for the clustering within postcode sector area.

Setting: Scotland.

Subjects: Subjects comprised 11075 male and 14052 female respondents.

Results: Lower consumption of high-fibre bread and potatoes/pasta/rice (among men and women), of cakes (men) and of cereals, meat, skimmed/semi-skimmed milk and green vegetables (women) in Glasgow was explained by socio-economic factors, as was higher consumption of non-diet soft drinks among women; lower consumption of ice cream, bread, cereals, meat and green vegetables (men) and high butter and salt consumption (women) in Greater Glasgow were not.

Conclusion: Associations between unhealthy eating and deprivation accounted for much of the tendency of people in Glasgow to have poor diets. Policies are needed to encourage improvements in diet in Glasgow and more effort is required to reduce social inequalities in eating habits. Glasgow's poor diet will remain unless problems associated with poverty are tackled.
\end{abstract}

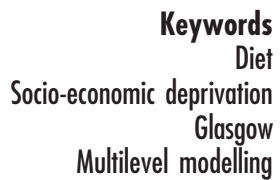

As well as suffering relatively poor health, Scotland as a whole has less favourable dietary habits than elsewhere in the UK; for instance, fruit and vegetable consumption is lower in Scotland than in England ${ }^{(1)}$. Attempts to explain Glasgow's poor health record ${ }^{(2)}$ have pointed to the elevated rates of negative health-related behaviours such as diet ${ }^{(3)}$. Further to the concept of a 'Scottish effect' on poor health - that is, elevated levels of disease and mortality over and above those expected from the profile of other known risk factors such as smoking, alcohol consumption and lack of physical activity ${ }^{(4,5)}-$ the existence of a 'Glasgow effect' on poor health has been proposed but remains unresolved ${ }^{(6)}$. The socio-economic composition of Glasgow differs from that of the rest of Scotland as a whole. Although in terms of area-based measures it contains wards at both ends of the deprivation spectrum, the Glasgow area is the most economically disadvantaged, with the highest proportions of wards in the $10 \%$ most deprived $^{(2)}$. In terms of individual socio- economic status, high levels of illness and mortality in Glasgow occur across all social classes but are especially concentrated in the lower status groups ${ }^{(7)}$. Whether poor diet in Glasgow relative to elsewhere in the country can be attributed to these socio-economic differences has not been addressed.

Quality of diet is socially patterned, with consumption of nutrient-rich diets high in whole grains, lean meats, fish, low-fat dairy products and fresh fruit and vegetables associated with higher socio-economic status and lower-quality, energy-dense diets - including elements such as refined grains and added fats - associated with deprivation ${ }^{(8)}$. In a systematic review of socio-economic differences in fruit and vegetable consumption in Europe, a higher socio-economic status (in terms of occupation and education) was found to be associated with greater intake ${ }^{(9)}$; this has been demonstrated nationally in Scotland ${ }^{(10)}$. Area deprivation has been found to predict lower consumption of fruit and vegetables even when individual socio-economic factors 
have been allowed for ${ }^{(11)}$ and social class and education have been shown to be independently associated with quality of diet ${ }^{(12)}$.

Regional comparisons of diet within Scotland have been made previously in Scottish Health Survey reports ${ }^{(13-15)}$ but did not have a specific focus on the differences between the Greater Glasgow area and the rest of the country. Subcountry regional comparisons of diet have been conducted elsewhere in Europe and North America ${ }^{(16,17)}$. On a smaller geographical scale, work investigating the role of locality within an area indicates that neighbourhood/environment plays a role in diet ${ }^{(18,19)}$; contextual effects at the sub-city area level should thus be considered.

The aims of the present work were to investigate differences in diet between adults living in Glasgow and the rest of Scotland and whether they can be explained by socio-economic factors. Multilevel analysis was used to account for the hierarchical data structure of individuals within small areas.

\section{Experimental methods}

The Scottish Health Surveys $1995^{(15)}, 1998^{(14)}$ and $2003^{(13)}$ were conducted to monitor health measures and healthrelated lifestyles of the Scottish population living in private households. The sample is described in detail in the survey reports ${ }^{(13-15)}$. Briefly, systematic selections of onethird of postcode sectors stratified by region and level of deprivation were made, letters were sent to random samples of addresses and information on health-related topics was collected from respondents by interviewers. The response rates for the surveys were 81\%, 77\% and $67 \%$ of all eligible households for the 1995, 1998 and 2003 surveys, respectively. Among other information data were collected on diet and socio-economic factors, and health board region and anonymized small area postcode sectors (harmonized, facilitating consistency across all three surveys) were recorded.

\section{Glasgow geography}

Generally, the Scottish Health Survey sampling strategy is designed to be representative at a grouped health board level but not at the individual health board level. However, Greater Glasgow - all three surveys preceded the split in 2006 of NHS Argyll \& Clyde Health Board into NHS Highlands and NHS Greater Glasgow \& Clyde - is the exception to this ${ }^{(20)}$, enabling reliable comparisons between the Glasgow area and the rest of Scotland based on the Scottish Health Survey samples. Residents in the Greater Glasgow Health Board region made up 17\% of those in the whole of Scotland.

\section{Dietary measures}

Two different modules of questions were used to assess eating habits in the Scottish Health Surveys ${ }^{(1)}$. One of these used a modified version of the validated Dietary Instrument of Nutrition Education questionnaire ${ }^{(21)}$ to assess informants' usual intake of a wide range of foods containing protein, carbohydrate, fat and fibre. The other, used in the 2003 survey only, assessed fruit and vegetable consumption, and was designed with the aim of providing sufficient detail to monitor the WHO-recommended minimum '5-a-day' policy on intake of $80 \mathrm{~g}$ portions of fruit and vegetables ${ }^{(22,23)}$. The items represented here correspond with those reported in the most recent Scottish Health Survey report ${ }^{(1)}$.

\section{Sugary foods and snacks}

The sugary foods and snacks items considered were consumption of: sweets or chocolate once per day or more; biscuits once per day or more; cakes/scones/pastries twice per week or more; ice cream once per week or more; non-diet soft drinks once per day or more; and crisps/other savoury snacks once per day or more.

Fibre- and starch-containing foods

Consumption of the following fibre-based and starchy foods was analysed: at least 2-3 slices of any bread per day; at least 2-3 slices of high-fibre bread per day; breakfast cereals at least 5-6 times per week; high-fibre cereal at least 5-6 times per week; potatoes/pasta/rice 5 times or more per week; and chips twice or more per week.

\section{Meat and fish}

Meat was defined as beef, lamb or pork and consumption was considered in terms of whether or not the respondent said they usually ate meat more than twice per week. Data were available from the surveys in 1995 and 2003. Respondents were categorized according to whether or not they said they ate meat products (e.g. pies, bridies, burgers) two or more times per week. Data were again available from the surveys in 1995 and 2003. Consumption of poultry twice per week and white and oily fish once per week or more was also analysed.

\section{Spreading fats and dairy products}

Aspects of dairy products analysed were use of butter on bread and consumption of skimmed or semi-skimmed milk.

\section{Salt}

Data on salt were considered in terms of whether or not the respondent said they usually add salt to their food (with or without tasting it first) at the table. Data were available for all three surveys.

\section{Dietary supplements}

Respondents were asked whether they took dietary supplements such as vitamins, fish oils and minerals. 


\section{Fruit and vegetable consumption}

In the 2003 survey, respondents were asked about the total number of portions (one portion $=80 \mathrm{~g}$ ) of vegetables (fresh, frozen or canned), vegetables in composites (e.g. vegetable curry), salads, pulses, fruit (fresh, frozen or canned), dried fruit and fruit in composites (e.g. apple pie) consumed in the $24 \mathrm{~h}$ preceding the interview ${ }^{(1)}$. Respondents were classified according to whether or not they ate five or more portions of fruit and vegetables per day; these data were available from the 2003 survey only. In the 1995 and 1998 surveys respondents were asked how often they usually ate cooked green vegetables such as peas, broccoli, cabbage, spinach, cauliflower and green beans ${ }^{(24)}$; they were classified according to whether or not they said they ate five or more portions of cooked green vegetables per week. The analyses were based on data from 1995 and 1998 health surveys only, since 2003 data were not available in a comparable form.

\section{Socio-economic factors}

Four socio-economic measures were available and compatible for all three surveys: the (1991) area-based Carstairs index of material deprivation ${ }^{(25)}$, occupation-based social class $^{(26)}$ of household chief income earner, educational qualification attainment and economic activity.

The Carstairs index is created using four national census data variables from the 1991 Great Britain census - namely, car ownership, household overcrowding, low social class and male unemployment - at the level of the postcode sector (average population of about 5000). In the present report, quintiles of the Carstairs index are used for the presentation of distributions; however, the continuous values were used in formal analyses. The possibility of non-linear relationships between area deprivation and risk factors/health outcomes was allowed for by the inclusion of a quadratic deprivation term in models.

Use of the Registrar General's social class of chief income earner enables the capturing of the social advantage of a household. When presenting data on the composition of the sample, social class was considered in its original six distinct groups, but for analyses it was grouped into three: professional/intermediate, skilled (manual/non-manual) and partly skilled/unskilled.

Respondents' highest educational qualifications were categorized as none, below degree level or degree/above degree-level qualification. Degree-level qualifications include first and higher university degrees and professional qualifications.

Individuals' employment status was considered in four groups: employed, unemployed, retired or economically inactive.

\section{Statistical methods}

Baseline percentages and standard errors for demographic and dietary items were calculated by area of residence - Glasgow and the rest of Scotland - with statistical significance of the differences by area given by $P$ values from Pearson $\chi^{2}$ tests. The extent to which differences in dietary measures between Glasgow and the rest of Scotland are explained by the differential socio-economic factors can be examined by comparing age- and survey year-adjusted results with those also adjusted for socioeconomic factors. First, logistic regression was applied to model the age- and survey year-adjusted relationship between the outcome - for example, whether or not the respondent usually adds salt to food at the table - and the explanatory factor - living in Greater Glasgow Health Board region compared with elsewhere in Scotland. Fully adjusted analysis incorporated further adjustment by socioeconomic factors (Carstairs area deprivation index, social class of household chief income earner, economic activity and educational qualification) allowing assessment of the effect of socio-economic factors on the relationship between Greater Glasgow residence and the outcome. All logistic regression models were fitted within a multilevel framework to account for the data hierarchy of individuals within postcode sector areas. This is appropriate since the assumption of independence required for standard regression modelling is violated by the correlation of outcomes between individuals living in the same area.

Like most surveys, the Scottish Health Surveys were unable to obtain information from an exactly representative sample of everyone within the population of interest. To avoid biased results arising from non-response it was necessary to adjust the data by differentially weighting survey respondents on a combination of probabilities. The weighting strategy was used in the original reporting of the Scottish Health Survey results and has been outlined elsewhere ${ }^{(20)}$; briefly, it was designed to take account of differential selection of postcode sectors, households and individuals as well as ensuring that the weighted sample of household members matched population estimates for age/sex and health boards.

\section{Results}

Of the 11075 (43.6\% of adults) men and 14052 (56.4\% of adults) women participating, 1611 (14.5\% of men) and 2195 (15.6\% of women), respectively, lived in the Greater Glasgow Health Board area (Table 1). Mean age was $42 \cdot 6$ years overall; $42 \cdot 3$ years for Glasgow and $42 \cdot 6$ years for the rest of Scotland. In Glasgow, $49 \cdot 1 \%$ of men and $51 \cdot 5 \%$ of women lived in areas in the most deprived quintile compared with $14 \cdot 3 \%$ and $14 \cdot 6 \%$, respectively, for the rest of the country (Table 1). Distributions by social class were similar, but Glasgow had less favourable economic activity and educational qualification compositions.

Among men, consumption of high-fibre bread, breakfast cereals, potatoes/pasta/rice, meat and green vegetables were significantly lower in Greater Glasgow than in the rest of Scotland (Table 1). They were also less likely to 
Table 1 Demographic and socio-economic characteristics and dietary habits by place of residence and sex: data from the 1995, 1998 and 2003 Scottish Health Surveys

\begin{tabular}{|c|c|c|c|c|c|c|c|c|c|c|}
\hline & \multicolumn{5}{|c|}{ Men } & \multicolumn{5}{|c|}{ Women } \\
\hline & \multicolumn{2}{|c|}{ Greater Glasgow } & \multicolumn{2}{|c|}{ Rest of Scotland } & \multirow[b]{3}{*}{$P$} & \multirow{2}{*}{\multicolumn{2}{|c|}{$\frac{\text { Greater Glasgow }}{n 2195(15 \cdot 6 \%)}$}} & \multirow{2}{*}{\multicolumn{2}{|c|}{$\frac{\text { Rest of Scotland }}{n 11857(84 \cdot 4 \%)}$}} & \multirow[b]{3}{*}{$P$} \\
\hline & \multicolumn{2}{|c|}{$n 1611(14.5 \%)$} & \multicolumn{2}{|c|}{ n $9464(85 \cdot 5 \%)$} & & & & & & \\
\hline & $\%$ & SE & $\%$ & SE & & $\%$ & SE & $\%$ & SE & \\
\hline \multicolumn{11}{|l|}{ Age (years) } \\
\hline $16-24$ & $17 \cdot 4$ & $1 \cdot 2$ & $16 \cdot 3$ & 0.5 & & $15 \cdot 8$ & $1 \cdot 0$ & $14 \cdot 9$ & 0.4 & \\
\hline $25-34$ & $20 \cdot 9$ & $1 \cdot 2$ & $20 \cdot 9$ & 0.5 & & $19 \cdot 7$ & 0.9 & $20 \cdot 2$ & 0.4 & \\
\hline $35-44$ & $20 \cdot 2$ & $1 \cdot 1$ & $20 \cdot 7$ & 0.5 & & $21 \cdot 6$ & $1 \cdot 0$ & $19 \cdot 9$ & 0.4 & \\
\hline $45-54$ & $18 \cdot 0$ & $1 \cdot 1$ & $18 \cdot 1$ & 0.4 & & $16 \cdot 6$ & 0.9 & $17 \cdot 8$ & 0.4 & \\
\hline $55-64$ & $14 \cdot 1$ & 0.9 & $14 \cdot 7$ & 0.4 & & $14 \cdot 4$ & 0.8 & $15 \cdot 1$ & 0.3 & \\
\hline $65-74$ & $7 \cdot 5$ & 0.6 & $7 \cdot 1$ & 0.3 & & $8 \cdot 3$ & 0.6 & $8 \cdot 4$ & 0.3 & \\
\hline 75 and over & $1 \cdot 8$ & 0.3 & $2 \cdot 2$ & $0 \cdot 1$ & $0 \cdot 871$ & $3 \cdot 5$ & 0.4 & $3 \cdot 7$ & 0.2 & 0.479 \\
\hline \multicolumn{11}{|l|}{ Carstairs quintile } \\
\hline 1 (least deprived) & $20 \cdot 9$ & $1 \cdot 2$ & $23 \cdot 2$ & 0.5 & & $19 \cdot 7$ & $1 \cdot 0$ & $22 \cdot 8$ & 0.4 & \\
\hline 2 & $7 \cdot 0$ & $0 \cdot 7$ & $20 \cdot 3$ & 0.5 & & $7 \cdot 3$ & 0.6 & $19 \cdot 7$ & 0.4 & \\
\hline 3 & $10 \cdot 6$ & 0.9 & $21 \cdot 4$ & 0.5 & & $9 \cdot 3$ & $0 \cdot 7$ & $20 \cdot 9$ & 0.4 & \\
\hline 4 & $12 \cdot 4$ & 0.9 & $20 \cdot 9$ & 0.5 & & $12 \cdot 2$ & 0.8 & $21 \cdot 9$ & 0.4 & \\
\hline 5 (most deprived) & $49 \cdot 1$ & $1 \cdot 4$ & $14 \cdot 3$ & 0.4 & $>0.001$ & $51 \cdot 5$ & $1 \cdot 2$ & $14 \cdot 6$ & 0.4 & $>0.001$ \\
\hline Social class & & & & & & & & & & \\
\hline I & $6 \cdot 8$ & $0 \cdot 7$ & $6 \cdot 3$ & 0.3 & & $5 \cdot 9$ & 0.6 & $5 \cdot 8$ & 0.3 & \\
\hline II & $24 \cdot 7$ & $1 \cdot 2$ & $24 \cdot 3$ & 0.5 & & $22 \cdot 5$ & $1 \cdot 0$ & $24 \cdot 3$ & 0.4 & \\
\hline III & $43 \cdot 0$ & $1 \cdot 4$ & $45 \cdot 0$ & 0.6 & & $42 \cdot 2$ & $1 \cdot 2$ & $45 \cdot 0$ & 0.5 & \\
\hline IV & $13 \cdot 5$ & $1 \cdot 0$ & $15 \cdot 4$ & 0.4 & & $13 \cdot 7$ & $0 \cdot 8$ & $15 \cdot 2$ & 0.4 & \\
\hline V & $5 \cdot 2$ & 0.5 & $5 \cdot 2$ & 0.3 & 0.527 & $9 \cdot 2$ & 0.6 & $5 \cdot 8$ & 0.2 & $>0.001$ \\
\hline Unknown & $6 \cdot 7$ & $0 \cdot 8$ & $3 \cdot 8$ & 0.3 & $>0.001$ & $6 \cdot 5$ & 0.6 & $3 \cdot 9$ & 0.2 & $>0.001$ \\
\hline Economic activity status & & & & & & & & & & \\
\hline Employed & $56 \cdot 4$ & $1 \cdot 4$ & $67 \cdot 8$ & 0.5 & & $47 \cdot 2$ & $1 \cdot 2$ & $53 \cdot 8$ & 0.5 & \\
\hline Unemployed & $9 \cdot 3$ & $0 \cdot 8$ & $6 \cdot 2$ & 0.3 & & $3 \cdot 0$ & 0.4 & $3 \cdot 2$ & 0.2 & \\
\hline Retired & $10 \cdot 9$ & $0 \cdot 7$ & $10 \cdot 3$ & 0.3 & & $13 \cdot 6$ & 0.7 & $13 \cdot 9$ & 0.3 & \\
\hline Economically inactive & $22 \cdot 8$ & $1 \cdot 2$ & $15 \cdot 6$ & 0.4 & $>0.001$ & $36 \cdot 0$ & $1 \cdot 1$ & $29 \cdot 0$ & 0.5 & $>0.001$ \\
\hline Unknown & $0 \cdot 7$ & 0.3 & $0 \cdot 2$ & 0.0 & $>0.001$ & 0.3 & $0 \cdot 1$ & 0.2 & $0 \cdot 1$ & $>0.001$ \\
\hline Education & & & & & & & & & & \\
\hline No qualification & $40 \cdot 7$ & $1 \cdot 3$ & $34 \cdot 5$ & 0.5 & & $43 \cdot 5$ & $1 \cdot 2$ & $36 \cdot 9$ & 0.5 & \\
\hline Below degree level & $39 \cdot 4$ & $1 \cdot 4$ & $48 \cdot 6$ & 0.6 & & $41 \cdot 6$ & $1 \cdot 2$ & $48 \cdot 2$ & 0.5 & \\
\hline Degree level or above & $19 \cdot 1$ & $1 \cdot 1$ & $16 \cdot 7$ & 0.4 & $>0.001$ & $14 \cdot 3$ & 0.8 & $14 \cdot 7$ & 0.4 & $>0.001$ \\
\hline Unknown & $0 \cdot 8$ & $0 \cdot 3$ & $0 \cdot 3$ & $0 \cdot 1$ & $>0.001$ & $0 \cdot 6$ & 0.2 & 0.3 & $0 \cdot 1$ & $>0.001$ \\
\hline Sugary foods and snacks & & & & & & & & & & \\
\hline Sweets or chocolate $\geq 0$ once $/ \mathrm{d}^{*}$ & $24 \cdot 7$ & $1 \cdot 5$ & $24 \cdot 7$ & 0.6 & 0.982 & $27 \cdot 5$ & $1 \cdot 3$ & $26 \cdot 3$ & 0.6 & 0.389 \\
\hline Biscuits $\geq 0$ once $/ d^{*}$ & $37 \cdot 4$ & $1 \cdot 6$ & $40 \cdot 3$ & $0 \cdot 7$ & $0 \cdot 105$ & $34 \cdot 8$ & $1 \cdot 4$ & $33 \cdot 4$ & 0.6 & $>0.001$ \\
\hline Cakes/scones/pastries $\geq$ twice/week* & $29 \cdot 2$ & $1 \cdot 5$ & $33 \cdot 1$ & 0.7 & 0.024 & $31 \cdot 1$ & $1 \cdot 3$ & $30 \cdot 3$ & 0.6 & 0.547 \\
\hline Ice cream $\geq$ once/week $^{*}$ & $33 \cdot \overline{7}$ & $1 \cdot 6$ & $38 \cdot 6$ & 0.7 & 0.007 & $29 \cdot 3$ & $1 \cdot 3$ & $32 \cdot 1$ & 0.6 & 0.054 \\
\hline Non-diet soft drinks $\geq$ once/d & $33 \cdot 1$ & $1 \cdot 3$ & $31 \cdot 9$ & 0.6 & $0 \cdot 418$ & $24 \cdot 9$ & $1 \cdot 1$ & $21 \cdot 1$ & 0.4 & 0.001 \\
\hline Crisps/other savoury snacks $\geq$ once/d $\mathrm{d}^{*}$ & $22 \cdot 3$ & $1 \cdot 5$ & $22 \cdot 8$ & 0.6 & 0.788 & $19 \cdot 8$ & $1 \cdot 2$ & $18 \cdot 6$ & 0.5 & 0.338 \\
\hline Fibre and starch & & & & & & & & & & \\
\hline Any bread $\geq 2-3$ slices $/ d$ & $87 \cdot 4$ & 0.9 & $89 \cdot 7$ & 0.4 & 0.015 & $79 \cdot 0$ & $1 \cdot 0$ & $79 \cdot 3$ & 0.4 & $0 \cdot 751$ \\
\hline High-fibre bread $\geq 2-3$ slices/d & $21 \cdot 5$ & $1 \cdot 1$ & $26 \cdot 4$ & 0.5 & $>0.001$ & $28 \cdot 2$ & $1 \cdot 1$ & $32 \cdot 0$ & 0.5 & 0.001 \\
\hline Breakfast cereals $\geq 5-6$ times/week & $38 \cdot 4$ & $1 \cdot 3$ & $45 \cdot 6$ & 0.6 & $>0.001$ & $43 \cdot 0$ & $1 \cdot 2$ & $46 \cdot 3$ & 0.5 & 0.008 \\
\hline High-fibre cereals $\geq 5-6$ times/week & $21 \cdot 3$ & $1 \cdot 1$ & $24 \cdot 0$ & 0.5 & 0.028 & $22 \cdot 9$ & $1 \cdot 0$ & $27 \cdot 2$ & 0.5 & $>0.001$ \\
\hline Potatoes/pasta/rice $\geq 5$ times/week & $53 \cdot 3$ & $1 \cdot 4$ & $58 \cdot 1$ & 0.6 & 0.001 & $57 \cdot 1$ & $1 \cdot 2$ & $62 \cdot 0$ & 0.5 & $>0.001$ \\
\hline Chips $\geq 2$ times/week* & $44 \cdot 9$ & $1 \cdot 7$ & $45 \cdot 0$ & 0.7 & 0.956 & $32 \cdot 7$ & $1 \cdot 4$ & $31 \cdot 4$ & 0.6 & 0.384 \\
\hline Meat and fish & & & & & & & & & & \\
\hline Meat (beef, lamb, pork) $\geq$ twice/week ${ }^{*}$ & $61 \cdot 6$ & $1 \cdot 7$ & $68 \cdot 4$ & 0.7 & $>0.001$ & $51 \cdot 4$ & $1 \cdot 4$ & $56 \cdot 9$ & 0.6 & $>0.001$ \\
\hline Meat products $\geq$ twice/week ${ }^{*}$ & $45 \cdot 3$ & $1 \cdot 7$ & $41 \cdot 7$ & 0.7 & 0.048 & $25 \cdot 4$ & $1 \cdot 3$ & $23 \cdot 5$ & 0.6 & $0 \cdot 147$ \\
\hline Poultry $\geq$ twice/week* & $58 \cdot 0$ & $1 \cdot 7$ & $56 \cdot 1$ & 0.7 & $0 \cdot 284$ & $58 \cdot 9$ & $1 \cdot 4$ & $59 \cdot 2$ & 0.6 & 0.865 \\
\hline White fish $\geq$ once/week & $52 \cdot 2$ & $1 \cdot 4$ & $53 \cdot 6$ & 0.6 & 0.364 & $51 \cdot 2$ & $1 \cdot 2$ & $51 \cdot 1$ & 0.5 & 0.942 \\
\hline Oily fish $\geq$ once/week & $22 \cdot 3$ & $1 \cdot 8$ & $20 \cdot 5$ & 0.7 & $0 \cdot 249$ & $23 \cdot 0$ & $1 \cdot 6$ & $21 \cdot 2$ & 0.6 & 0.205 \\
\hline Spreading fats and dairy produce & & & & & & & & & & \\
\hline Uses butter on bread* ${ }^{*}$ & $25 \cdot 6$ & $1 \cdot 5$ & $25 \cdot 1$ & 0.6 & $0 \cdot 709$ & $30 \cdot 6$ & $1 \cdot 3$ & $25 \cdot 5$ & 0.6 & $>0.001$ \\
\hline Skimmed or semi-skimmed milk & $65 \cdot 8$ & $1 \cdot 3$ & $64 \cdot 0$ & 0.6 & $0 \cdot 213$ & $66 \cdot 1$ & $1 \cdot 1$ & $71 \cdot 1$ & 0.5 & $>0.001$ \\
\hline Fruit and vegetables & & & & & & & & & & \\
\hline Fruit and vegetables $\geq 5$ portions $/ \mathrm{d} t$ & $21 \cdot 2$ & $1 \cdot 8$ & $19 \cdot 6$ & 0.8 & 0.395 & $20 \cdot 5$ & $1 \cdot 6$ & $22 \cdot 5$ & $0 \cdot 7$ & 0.244 \\
\hline Green vegetables $\geq 5$ times/week ${ }^{*}$ & $31 \cdot 4$ & $1 \cdot 6$ & $40 \cdot 9$ & 0.7 & $>0.001$ & $39 \cdot 5$ & $1 \cdot 4$ & $45 \cdot 4$ & 0.6 & $>0.001$ \\
\hline Usually adds salt to food at the table & $51 \cdot 5$ & $1 \cdot 4$ & $47 \cdot 3$ & 0.6 & 0.005 & $44 \cdot 5$ & $1 \cdot 2$ & $36 \cdot 2$ & 0.5 & $>0.001$ \\
\hline Takes dietary supplements & $17 \cdot 6$ & $1 \cdot 2$ & $17 \cdot 3$ & 0.5 & 0.803 & $25 \cdot 3$ & $1 \cdot 2$ & $28 \cdot 3$ & 0.5 & 0.027 \\
\hline
\end{tabular}

*Based on 1995 and 2003 data only.

tBased on 2003 data only. 
eat ice cream at least once per week. In women, the consumption of high-fibre bread, breakfast cereals, highfibre cereal, potatoes/pasta/rice, meat, skimmed/semiskimmed milk and green vegetables were significantly lower and drinking non-diet soft drinks, use of butter and addition of salt to food at the table was significantly higher in Greater Glasgow than the rest of the country.

\section{Age- and survey year-adjusted results}

In age- and survey year-adjusted logistic regression models, men living in Greater Glasgow were significantly less likely to consume any bread, high-fibre bread, breakfast cereals, potatoes/pasta/rice, meat and green vegetables compared with the rest of Scotland (Table 2). They were also less likely to eat cakes/scones/pastries and ice cream. There were no significant differences between men living in Greater Glasgow and those in the rest of Scotland in consumption of sweets and chocolates, biscuits, non-diet soft drinks, crisps/other savoury snacks, high-fibre cereal, chips, meat products, poultry, white fish, oily fish, butter, skimmed or semi-skimmed milk, salt, dietary supplements, or fruit and vegetables.

Women in Greater Glasgow were significantly less likely than those in the rest of Scotland to eat high-fibre bread, breakfast cereals, high-fibre cereal, potatoes/pasta/rice, meat, skimmed/semi-skimmed milk and green vegetables. The Greater Glasgow women were significantly more likely to use butter and to add salt to food at the table. Differences were not significant for sweets and chocolates, biscuits, cakes/scones/pastries, ice cream, non-diet soft drinks, crisps/other savoury snacks, any bread, chips, meat products, poultry, white fish, oily fish, dietary supplements, or fruit and vegetables.

\section{Age-, survey year-and socio-economic-adjusted results}

Accounting for socio-economic factors impacted on results for some but not all of the dietary items. Among men, results for high-fibre bread, cakes/scones/pastries and potatoes/pasta/rice became non-significant, whereas those for ice cream, bread, cereals, meat and green vegetables remained significantly lower following socioeconomic adjustment. It emerged that men in Greater Glasgow were significantly more likely than those in the rest of Scotland to consume poultry, skimmed/semiskimmed milk and potatoes/pasta/rice after adjustment for socio-economic factors.

In women, while butter and salt consumption remained significantly higher among those living in Greater Glasgow once account of socio-economic factors had been taken, results for high-fibre bread, cereals, high-fibre cereals, potatoes/pasta/rice, meat, skimmed/ semi-skimmed milk and green vegetables became nonsignificant. Where previously results for the consumption of poultry and oily fish were non-significant, accounting for socio-economic factors revealed significantly higher consumption levels in Greater Glasgow.

\section{Discussion}

In the present study of over 25000 adults, the Greater Glasgow area was found to have an unfavourable dietary profile compared with the rest of Scotland in terms of a number of items, some but not all of which could be explained by differences in socio-economic factors. Among both men and women, lower consumption of high-fibre bread and potatoes/pasta/rice was explained by socioeconomic factors. Additionally, lower consumption of cereals (any and high-fibre), meat, skimmed/semi-skimmed milk and green vegetables among women was accounted for by socio-economic factors, as was that of cakes among men. Higher salt consumption among men and non-diet soft drinks among women in Greater Glasgow were also explained. However, there remained a residue of low bread, cereals, meat and green vegetable consumption among men and high butter and salt consumption among women in Greater Glasgow. On a positive note, ice cream consumption was significantly lower among men, while significantly higher levels of consumption of poultry among both men and women, skimmed/semi-skimmed milk along with recommended fruit and vegetable intake among men and oily fish among women in Greater Glasgow emerged on adjustment for socio-economic factors. For some foodstuffs - sweets and chocolates, biscuits, crisps/other savoury snacks, chips, meat products, white fish and dietary supplements among both men and women; non-diet soft drinks, high-fibre cereal, oily fish and butter among men; and cakes/scones/pastries, ice cream, any bread and fruit and vegetables among women - the rest of the country was found to have equivalent levels of consumption.

Previously conducted sub-country regional comparison of diet in Italy identified geographical variations in food types consumed ${ }^{(16)}$. A study in Canada comparing dietary intake and habits by region found variations by socioeconomic status as well as urban/rural locale ${ }^{(17)}$.

\section{Limitations}

Most of the Scottish Health Survey data come from self-completed questionnaires and, therefore, involve self-reported measures without objective or external validation. The reliability of some measures, especially diet, is questionable as respondents are known to provide answers that convey more favourable nutritional profiles than objective data suggest. Nevertheless, the survey data remain useful for carrying out comparisons across population groups within similar periods of time as carried out in the present study.

Since they do not provide comprehensive records of the entire diet, health surveys are not as thorough as FFQ and methods such as those used in the Expenditure and 


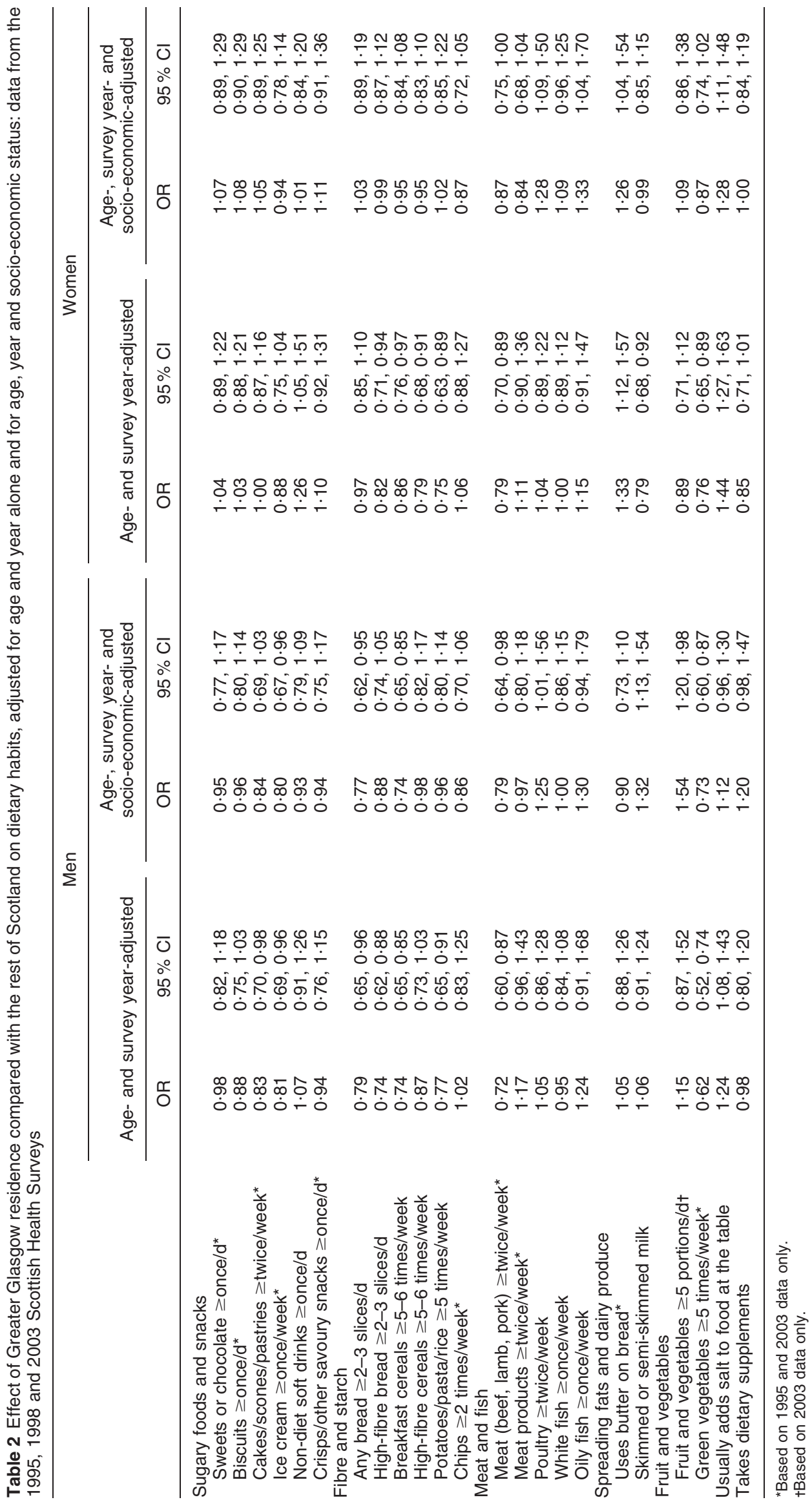


Food Survey ${ }^{(27)}$ in terms their ability to measure dietary intake accurately. However, for monitoring trends over time and for the purposes of intra-survey geographical comparisons such as those in the current report, Scottish Health Survey data ${ }^{(1)}$ provide useful and valid bases for analyses $^{(28)}$.

Response rates were not equal across the country, with lower rates achieved in Greater Glasgow than in Scotland as a whole. However, with response rates in Greater Glasgow ranging from $80 \%$ (compared with $81 \%$ for the entire survey) in 1995 to $61 \%$ (compared with 67\% for the entire survey) in 2003, differences were not large. Differences in non-response rates by social class and area deprivation could potentially bias the results. Data on response rates by social class and area deprivation were not readily available so this could not be directly assessed, but given the similarity of response rates in Glasgow compared with those overall, there was no reason to believe this phenomenon was occurring to any great extent.

Since the bulk of extreme deprivation in Scotland is within Greater Glasgow, it was important to be mindful of the adjustment in the formal statistical modelling: as residence in the Glasgow area is highly correlated with living in a deprived area, working with the Carstairs index of area deprivation in a small number of categories could have led to inadvertent adjustment for 'Glasgow' and lead to spurious non-significant results after adjustment. Using the Carstairs index on a continuous scale, as was done in the formal analyses here, preserves the range of the distribution, and should have resolved this potential problem.

The socio-economic instruments used are not necessarily entirely representative of the aspects of material and social wealth which would ideally be measured, and as such are potentially flawed; use of area deprivation, individual social class, educational qualification attainment and employment status does not necessarily capture the full picture. For example, individual and household income, known to be related to dietary habits ${ }^{(29)}$, was not collected in all the Scottish Health Surveys. Residual confounding of the effects of socio-economic status (where they remain after adjustment) cannot be ruled out. Of course, within regions ${ }^{(30)}$ and Glasgow in particular $^{(31,32)}$ there are contrasts in the quality of diet which persist after account of individual socio-economic factors. Food choices are, of course, affected by availability and accessibility, which can vary according to the affluence of the locality ${ }^{(33)}$. The adjustment of models by postcode sector area here will have captured some of this. Area of residence effects in relation to dietary and other health-related habits extend to biological/anthropometric differences ${ }^{(34)}$.

Healthy eaters tend to have more favourable general health-related profiles, for example with relation to smoking, alcohol and exercise ${ }^{(35)}$; detrimental effects of deficient diet may be compounded by associated other poor lifestyle choices.

\section{Strengths}

The Scottish Health Surveys are based on representative samples of the population with relatively high response rates. They form an effective basis for consistent comparisons of different population groups and over time. The combination here of all these available data has enabled comparisons with increased power to detect differences where they exist.

The statistical methodology used was rigorous, encompassing weighting and multilevel modelling, with adjustment made for the effects of any differences over survey year; it is thus accurate and reliable. With the extra effort involved in obtaining codes for postcode sector area data consistent across all three surveys, the account taken of geographical data hierarchy is as robust as possible.

The findings indicate that the 'Glasgow effect' of poorer diet in the area compared with the rest of Scotland was in evidence for some but not all aspects of diet and was attributable to socio-economic factors for many foods, especially among women. The social patterning of many of the negative aspects of diet examined accounted for the tendency of the area to have high levels of poor diet, reflecting its unfavourable socio-economic position. Thus more should be done to reduce the social inequalities in healthy eating in Glasgow; recognizing the area's distinct demographics and their association with low consumption of healthy food such as high-fibre breads and cereals may be useful in customizing improved diet programmes ${ }^{(17)}$. Furthermore, policy makers addressing issues relating specifically to the Glasgow area should also be aware of the need to encourage a higher consumption of nutritious foods, such as vegetables, and lower intake of butter and salt across the entire social spectrum. Although some characteristics of the diet in Glasgow - for instance, higher poultry and skimmed/ semi-skimmed milk consumption - can be considered positive, in general - whether mediated by socio-economic factors for some foods, or in relation to all social groups for others - diet was poorer in the area compared with the rest of the country. Improving Glasgow's health thus remains inextricably linked to tackling the problems associated with deprivation and poverty, but targeted interventions are also required.

\section{Acknowledgements}

Our thanks go to David Walsh, Professor Carol Tannahill, Professor Phil Hanlon and Dr Maria Maynard for useful discussion. This work was funded by the Glasgow Centre for Population Health and the Chief Scientist Office of the Scottish Government Health Directorates (WBS Code U.1300.00.001). There are no conflicts of interest to declare. L.G. performed analyses, prepared the first draft of the manuscript and is the guarantor of the paper. 
A.H.L. contributed to the writing of the manuscript. Both authors were involved in the formulation of the research question.

\section{References}

1. Speight S, Wardle H \& Bromley C (2005) Fruit and vegetable consumption and eating habits. In The Scottish Health Survey 2003. vol. 2: Adult Health, pp. 75-150 [C Bromley, K Sprogston and N Shelton, editors]. Edinburgh: The Scottish Executive Department of Health.

2. Social Disadvantage Research Centre (2003) Scottish Indices of Deprivation 2003. Oxford: Department of Social Policy and Social Work, University of Oxford.

3. Shaw A, McMunn A \& Field J (editors) (2000) The Scottish Health Survey 1998. vol. 1. Edinburgh: The Stationery Office.

4. Hanlon P, Lawder RS, Buchanan D, Redpath A, Walsh D, Wood R, Bain M, Brewster DH \& Chalmers J (2005) Why is mortality higher in Scotland than in England and Wales? Decreasing influence of socioeconomic deprivation between 1981 and 2001 supports the existence of a 'Scottish effect'. J Public Health 27, 199-204.

5. Hanlon P, Walsh D, Buchanan D et al. (2001) Chasing the Scottish Effect. Why Scotland Needs a Step-change in Health If It Is To Catch Up With the Rest of Europe. Glasgow/ Edinburgh: Public Health Institute of Scotland/Information and Statistics Division of the Common Services Agency.

6. Walsh D, Taulbut M \& Hanlon P (2008) The Aftershock of Deindustrialisation: Trends in Mortality in Scotland and Other Post-industrial European Regions. Glasgow: Glasgow Centre for Population Health and NHS Health Scotland.

7. Leyland AH, Dundas R, McLoone P \& Boddy A (2007) Inequalities in Mortality in Scotland 1981-2001. Glasgow: MRC Social and Public Health Sciences Unit.

8. Darmon N \& Drewnowski A (2008) Does social class predict diet quality? Am J Clin Nutr 87, 1107-1117.

9. De Irala-Estevez J, Groth M, Johansson L, Oltersdorf U, Prattala R \& Martinez-Gonzalez M (2000) A systematic review of socio-economic differences in food habits in Europe: consumption of fruit and vegetables. Eur J Clin Nutr 54, 706-714.

10. Shelton NJ (2005) What not to eat: inequalities in healthy eating behaviour, evidence from the 1998 Scottish Health Survey. J Public Health 27, 36-44.

11. Shohaimi S, Welch A, Bingham S, Luben R, Day N, Wareham N \& Khaw KT (2004) Residential area deprivation predicts fruit and vegetable consumption independently of individual educational level and occupational social class: a cross sectional population study in the Norfolk cohort of the European Prospective Investigation into Cancer (EPIC-Norfolk). J Epidemiol Community Health 58, 686-691.

12. Turrell G, Hewitt B, Patterson C, Oldenburg B \& Gould T (2002) Socioeconomic differences in food purchasing behaviour and suggested implications for diet-related health promotion. J Hum Nutr Diet 15, 355-364.

13. Bromley C, Sproston K \& Shelton N (editors) (2005) The 2003 Scottish Health Survey (4 vols). Edinburgh: The Stationery Office.

14. Shaw A, McMunn A \& Field J (editors) (2000) The 1998 Scottish Health Survey (2 vols). Edinburgh: The Stationery Office.

15. Dong W \& Erens B (editors) (1997) Scottish Health Survey 1995 (2 vols). Edinburgh: The Stationery Office.
16. Turrini A, Saba A, Perrone D, Cialfa E \& D'Amicis A (2001) Food consumption patterns in Italy: the INN-CA Study 1994-1996. Eur J Clin Nutr 55, 571-588.

17. Minaker LM, McCargar L, Lambraki I, Jessup L, Driezen P, Calengor K \& Hanning RM (2006) School region socioeconomic status and geographic locale is associated with food behaviour of Ontario and Alberta adolescents. Can J Public Health 97, 357-361.

18. Ellaway A \& Macintyre S (1996) Does where you live predict health related behaviours?: a case study in Glasgow. Health Bull (Edinb) 54, 443-446.

19. Morland K, Wing S \& Roux AD (2002) The contextual effect of the local food environment on residents' diets: The Atherosclerosis Risk in Communities Study. Am J Public Health 92, 1761-1767.

20. Craig R, Deverill C, Pickering K \& Prescott A (2005) Methodology and response. In The Scottish Health Survey 2003. vol. 4: Technical Report, pp. 7-49 [S Bromley, K Sproston and N Shelton, editors]. Edinburgh: The Scottish Executive Department of Health.

21. Roe L, Strong C, Whiteside C, Neil A \& Mant D (1994) Dietary intervention in primary care: validity of the DINE method for assessment. Fam Pract 11, 375-381.

22. Cullum A (2003) Increasing fruit and vegetable consumption: the 5 A DAY programme. Nutr Bull 28, 159-163.

23. World Health Organization (2003) Diet, Nutrition and the Prevention of Chronic Diseases. Report of a Joint FAO/WHO Expert Consultation. WHO Technical Report Series no. 916. Geneva: WHO.

24. Deepchand K, Shaw A \& Field J (2000) Eating habits. In The Scottish Health Survey 1998. vol. 1, pp. 319-385 [A Shaw, A McMunn and J Field, editors]. Edinburgh: The Scottish Executive Department of Health.

25. Carstairs V \& Morris R (1991) Deprivation and Health in Scotland. Aberdeen: Aberdeen University Press.

26. Leete R \& Fox J (1977) Registrar General's social classes: origins and uses. Popul Trends $\mathbf{8}, 1-7$.

27. Department for Environment Food and Rural Affairs (2006) Family Food in 2004-05. London: The Stationery Office.

28. Wrieden WL, Barton KL, Armstrong J \& McNeill G (2006) A Review of Food Consumption and Nutrient Intakes from National Surveys in Scotland: Comparison to the Scottish Dietary Targets. Aberdeen: Food Standards Agency Scotland.

29. Turrell G \& Kavanagh AM (2006) Socio-economic pathways to diet: modelling the association between socioeconomic position and food purchasing behaviour. Public Health Nutr 9, 375-383.

30. Cummins S \& Macintyre S (2006) Food environments and obesity - neighbourhood or nation? Int J Epidemiol 35, 100-104.

31. Forsyth A, Macintyre S \& Anderson A (1994) Diets for disease? Intraurban variation in reported food consumption in Glasgow. Appetite 22, 259-274.

32. Gray L (2007) Comparisons of Health-related Behaviours and Health Measures Between Glasgow and the Rest of Scotland. Glasgow: Glasgow Centre for Population Health.

33. Sooman A, Macintyre S \& Anderson A (1993) Scotland's health - a more difficult challenge for some? The price and availability of healthy foods in socially contrasting localities in the west of Scotland. Health Bull (Edinb) 51, 276-284.

34. Ellaway A, Anderson A \& Macintyre S (1997) Does area of residence affect body size and shape? Int J Obes Relat Metab Disord 21, 304-308.

35. Anderson A \& Hunt K (1993) Who are the healthy eaters? Eating patterns and health promotion in the west of Scotland. Health Educ J 51, 3-10. 